\title{
Thunderstorms and Other Features of the Weather.
}

M R. BROOKS has compiled a very valuable monograph on the thunderstorms of the world. ${ }^{1}$ A " day with thunder" is the unit employed, and records are used from 3265 stations, 2680 being in Europe. Maps show the percentage of days with thunder for the whole year, and for each half-year. It is assumed that thunder can only be heard up to ten or twelve miles, and that on the average it will only be recorded when occurring within six miles of any station. Mr. Brooks shares the gerteral opinion that thunder is not heard farther than about twelve miles, but this distance may frequently be doubled at night, and sometimes tripled.

The maps show six areas of maximum frequency of thunder, Madagascar, Central Brazil, Panama, Southern Mexico, Central Africa, and Java, in which island thunder occurs on 61 per cent. of all days. Areas with thunder on less than I per cent. of all days are Greenland, north Iceland, north Norway, the north coast of North America, the Arctic Ocean, and the Antarctic Continent. There are areas of low frequency on the west coasts of North and of South America, and on the west coasts of South and North Africa; the latter area extends across the Sahara into Arabia, the other three do not extend far inland, but all of them go a long way out into the ocean. All these regions are on the east side of anticyclonic areas in positions where winds from a polar direction keep the surface temperature cool; they are also in regions of cool ocean currents, and, though Mr. Brooks does not actually point it out, these may have something to do with the low thunderstorm frequency; the Peru, the Benguela, the California, the Canaries, and the Labrador currents are all reflected in the isobronts; even the small cool current down the Korean coast shows its effect.

A very interesting map is given showing what percentage of thunder occurs in winter in western Europe; the 30 per cent. line extends down the Norwegian coast, embraces practically the whole of the British Isles, and crosses Brittany and the northwest coast of Spain; eastward the percentage decreases, but north-westward it increases to 75 per cent. for the region of Iceland and the Faröes. Another map illustrates the distribution of thunder over central Europe in July, and shows that the "chief maximum of thunderstorm frequency in Europe extends in a long narrow belt at the base of the northern slopes of the Alps."

It is estimated that over the whole globe $16,000,000$ thunderstorms occur per annum; if the average duration is one hour, there are 1800 storms occurring at any one time; if there are approximately 200 flashes per hour in a severe temperate, or an average 1 Air Ministry: Meteorological Office. Geophysical Memoirs, No. 24 : The Distribution of Thunderstorms over the Globe. By C. E. P. Brooks. (M.O. 254d.) Pp. $145-164+4$ plates. (London: H.M. Stationery Office,
I925.) 2 s. net. tropical storm, there will be roo flashes per second over the globe. The number thus estimated by $\mathrm{Mr}$. Brooks is of the same order as the frequency of atmospherics, which may all, therefore, be possibly due to lightning. In further sections are discussed the variation of thunder with season and with latitude over both land and sea, the diurnal variation and the effect of height on thunder frequency.

Mr. Brooks's work is a most important addition to the literature of the subject, and is one that no meteorologist can afford to be without; it will also be of value to those who take an interest in thunderstorms without being themselves meteorologists.

Dr. Sen ${ }^{2}$ has collected the records on wind components that have been published in the Geophysical Journal, and his paper is illustrated by tables and diagrams. The south-north and west-east components of the wind are discussed in relation to the annual and diurnal variation; maps show the averages of the gradient, the gradient wind, and the resultant wind for each month; and the growth of convection winds in summer-land and sea breezes-is investigated.

The scope of Mr. E. V. Newnham's work ${ }^{3}$ is best explained by the opening paragraph: "The object of this classification is to provide a ready means for discovering whether the conditions prevailing over the North Atlantic and Europe at any time bear any resemblance to situations that have arisen in the past at about the same time of the year, and, further, to bring into evidence any distributions of pressure which tend to recur and may be regarded as genuine types, and to determine the seasonal variations of such types."' The position of anticyclones is the basis of the classification; the region between latitudes $30^{\circ} \mathrm{N}$. and $80^{\circ} \mathrm{N}$., and longitudes $30^{\circ} \mathrm{E}$. and $70^{\circ} \mathrm{W}$., has been divided into ten areas to each of which a letter has been assigned; the position of anticyclones is shown by the capital letters of the areas over which they occur, while the position of depressions is shown by small letters.

The work must have involved an immense amount of labour; Table III. gives each of the 5478 days of the period concerned with the pressure distribution found on each, while Table IV. gives an index of the pressure distributions with the dates on which each occurred. It will prove of great assistance to those who are interested in investigating types of weather and changes in types; the summaries are in an extremely convenient form for reference.

$$
\text { C. J. P. C. }
$$

${ }^{2}$ Air Ministry: Meteorological Office. Geophysical Memoirs, No. 25 : Surface and Geostrophic Wind Components at Deerness, Holyhead, Great Yarmouth and Scilly. By Dr. Sachindra Nath Sen. (M.O. 254e.) Pp. 165-178+6 plates. (London: H.M. Stationery Office, 1925.) 2s. net. ${ }^{3}$ Air Ministry: Meteorological Office. Geophysical Memoirs, No. 26 : Classification of Synoptic Charts for the North Atlantic for 1896-rgro. By E. V. Newnham. (M.O. 254f.) Pp. I79-200+I plate. (London: H.M. Stationery Office, 1925.) 6s. net.

\section{The International Psycho-Analytical Congtess.}

(From a CORRESPONDENT.)

THE ninth international Psycho-Analytical Congress which assembled on September 3-5 at Bad Homburg, Germany, was marked by some interesting features. Unlike its predecessor which met at Salzburg at Easter I924, under the shadow of Prof. Freud's serious illness, the ninth congress was very happily able to begin its business by sending Prof. Freud a congratulatory telegram on his restoration to health.

As at the last three congresses, dating from 1920 the year which saw the first re-assembly since the pre-War period, many nations were represented, and by many distinguished names. In his presidential address, Dr. Karl Abraham, Director of the Berlin Psycho-Analytical Clinic, welcomed representatives, who with relatives and visitors numbered about two hundred, from Austria, France, Germany, Great Britain, Holland, Hungary, India, Poland, Switzerland, Russia, and the United States. Dr. Abraham expressed particular satisfaction at

NO. 2917 , VOL. 1167 